\title{
Formation and evolution of Sinian oil and gas pools in typical structures, Sichuan Basin, China
}

\author{
Yuan Haifeng, 2*, Liang Jiaju², Gong Deyu ${ }^{2}$, Xu Guosheng, ${ }^{1,}$, Liu Shugen ${ }^{1,2}$ \\ and Wang Guozhi ${ }^{1}$
}

\author{
${ }^{1}$ State Key Laboratory of Oil and Gas Reservoir Geology and Exploitation, Chengdu University of Technology, Sichuan \\ 610059, China \\ ${ }^{2}$ College of Energy Resources, Chengdu University of Technology, Sichuan 610059, China
}

(C) China University of Petroleum (Beijing) and Springer-Verlag Berlin Heidelberg 2012

\begin{abstract}
The only major breakthrough in the exploration of the Sinian of the Sichuan Basin has been the Weiyuan gas field. Taking the typical structures in the Sichuan Basin as examples, an apatite fission track simulation was applied to constrain the thermal evolutionary history of the source rocks in this study. Combined with trap formation and evolution, the formation, destruction, and accumulation history of the Sinian reservoirs were analyzed from a dynamic perspective. The Sinian reservoirs underwent several primary stages: the paleo-reservoir formation and destruction in the late Silurian, hydrocarbon recharge in the Permian-Triassic, the cracking of oil to gas and dissolved-gas in the late Triassic-Mid-Late Jurassic, and the exsolution and accumulation of dissolved-gas as a result of episodic uplift since the Late Cretaceous. The exsolution process of dissolved-gas is of great significance to the accumulation of natural gas. The formation of the Weiyuan gas field is also related to this process. The Sinian in the Sichuan Basin has a broad exploration prospect, and exploration targets focused on the Leshan-Longnüsi Paleouplift tectonic zone with weak influences on potential hydrocarbon reservoirs from the late tectonism and transformation.
\end{abstract}

Key words: Apatite fission track, Sinian reservoirs, Sichuan Basin

\section{Introduction}

The Sichuan Basin is a large hydrocarbon-rich superimposed basin in China (Fig. 1), with an area of $19 \times$ $10^{4} \mathrm{~km}^{2}$. The sedimentary covers of the basin were completely developed, with a total thickness of 6,000-12,000 m. A new round of hydrocarbon resource assessment completed in 2002 estimated that the total geological gas resources amount to $5.35 \times 10^{12} \mathrm{~m}^{3}$ in the Sichuan Basin, while the remaining geological gas resources were equal to $4.63 \times 10^{12} \mathrm{~m}^{3}$. By the end of 2009, the total proven reserves of natural gas were equal to $1.9 \times 10^{12} \mathrm{~m}^{3}$ in the Sichuan Basin, with the proven reserves of continental clastic rocks and marine layers accounting for $19.9 \%$ and $80.1 \%$, respectively. However, those of the Sinian Dengying Formation $\left(Z_{2} d n\right)$ only accounted for 2\% (Liu et al, 2011), indicating that the Sinian reservoirs in the Sichuan Basin still have a huge exploration potential.

The exploration for Sinian reservoirs in the Sichuan Basin has continued for more than 40 years, with the Weiyuan gas field and Ziyang gas reservoir discovered during this period, as well as gas-bearing structures such as Gaoshiti-

*Corresponding author. email: yhf870@yahoo.com.cn Received June 7,2011
Anpingdian and Longnüsi. However, no ideal exploration effect was achieved. In 2006, the Dingshan 1 well was drilled in Southeast Sichuan by the SINOPEC Exploration Southern Company. Except for some hydrocarbon discovered in the Sinian, no industrial gas flow was obtained. However, abundant bitumen was found in the pores, holes, and fractures of Sinian cores and microscopic thin sections. This indicated that a large hydrocarbon accumulation had once existed in the Sinian reservoirs, but might have been destroyed, transformed, or lost.

Recent exploration failed to achieve a breakthrough in the Sinian of the Sichuan Basin. This paper focuses on the formation and evolution of possible Sinian reservoirs in typical structures of the Sichuan Basin and provides a reference for further exploration.

\section{Characteristics of source rocks}

Overlaying the Dengying Formation $\left(Z_{2} d n\right)$, the Lower Cambrian strata of the Sichuan Basin mainly consist of black and dark gray shale, carbonaceous shale, or sandy shale. As sediments from a strongly reducing environment (Chen, 2010), the Lower Cambrian strata are some of the best hydrocarbon sources in the Sichuan Basin, with a thickness of 0-445 m (139 m on average, with the maximum in Southwest 


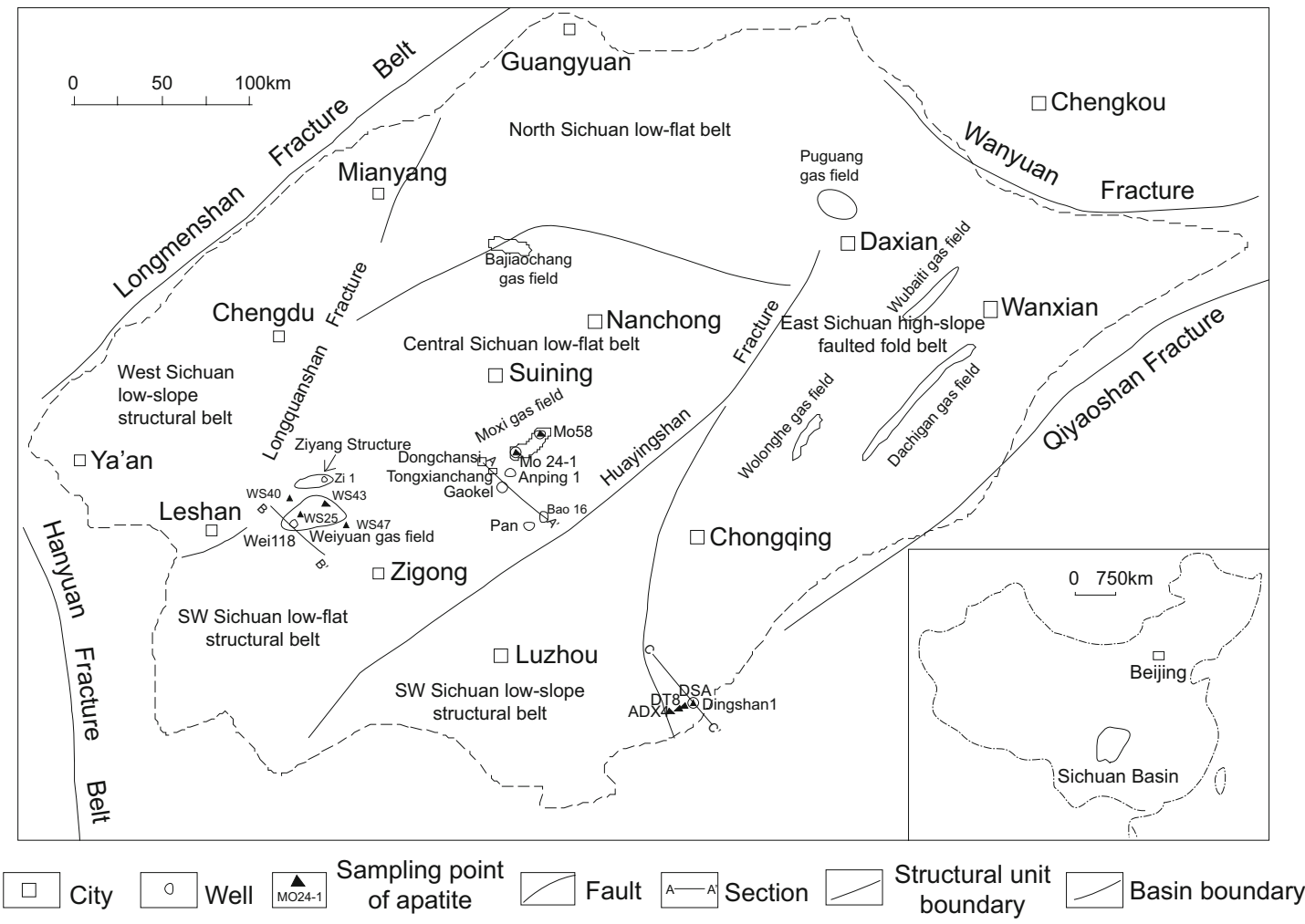

Fig. 1 Location map of typical structures of the Sichuan Basin

Sichuan). The Gongshen 1 well intersects Lower Cambrian strata $445 \mathrm{~m}$ thick. The total organic carbon (TOC) of the source rocks generally has a distribution of $0.5 \%-4.0 \%$. It is higher in the Weiyuan structure of the Southwest Sichuan, North and East Sichuan blocks, with values generally above $1 \%$ for type I organic matter. The black shale of the Lower Cambrian Qiongzhusi Formation has a thickness of 90-120 m in the Anpingdian and Gaoshiti structures of Central Sichuan, where the organic matter is mostly in a post-mature stage. The $R_{\mathrm{o}}$ has an average measured value of $2.86 \%$ in the Anping 1 well with kerogen of type I and an average total organic carbon of $2.18 \%$, showing a strong hydrocarbon generation capacity. The lower part of the Lower Cambrian Niutitang in the Dingshan structure of Southeast Sichuan mainly consists of gray black carbonaceous mudstones with a thickness of 124 $\mathrm{m}$. The organic carbon values at the bottom of the Niutitang range between $0.45 \%$ and $1.65 \%$. The average for the original organic carbon is $1.34 \%$ in the mudstone at the bottom of the Niutitang Formation, which is close to the standard for good source rocks. The hydrocarbon potential intensity is very high in the Lower Cambrian hydrocarbon sources of Sichuan $\mathrm{Xu}$, 1999), with an average of $1.33 \times 10^{15} \mathrm{~m}^{3}$. Currently, the $R_{\mathrm{o}}$ values of organic matter in the source rocks range between $2.0 \%$ and $5.0 \%$. This structure is in the post-mature stage, with kerogen pyrolysis gas and oil-cracking gas generated in its geological history.

\section{Reservoirs, cap rocks, and overburden rocks}

With a general thickness of $300-1,200 \mathrm{~m}$ in the Sichuan
Basin (Liu et al, 2007), the Sinian Dengying Formation $\left(Z_{2} d n\right)$ mainly consists of algal dolomite and granular dolomite. The existing Sinian core data showed that fractures and holes with a low matrix porosity and denser reservoirs were the main reservoir types in the Dengying Formation $\left(Z_{2} \mathrm{dn}\right)$.

The Sinian Dengying reservoirs in the Gaoke 1 well and Anping 1 well, Central Sichuan, mainly consist of variegated algal dolomite and powdery fine-grained dolomite of shallowwater carbonate platform facies. The average porosity is $1.51 \%-2.49 \%$ and $0.64 \%-2.60 \%$ in the fourth and third members, respectively, of the Sinian Dengying Formation in well Gaoke 1 . The permeability values of the effective

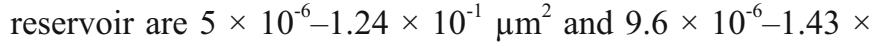
$10^{-4} \mu \mathrm{m}^{2}$ in the fourth and third members of the Dengying Formation, respectively. The reservoir property of the fourth member is comparatively good. The average porosity of the Sinian reservoirs is $1.85 \%$ in the Weiyuan gas field (11 wells) and $1.53 \%$ in the Ziyang gas-bearing areas (Liu et al, 2008a),

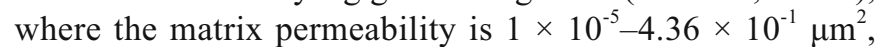
with an average value of $0.116 \times 10^{-3} \mu^{2}$. The main reservoir spaces consist of solution pores, solution fractures, and dolomite intergranular pores.

The Sinian Dengying reservoirs in well Dingshan 1 mainly consist of fine-grained dolomite and sparry dolarenite. The average porosity of 102 core samples is $1.78 \%$ with the porosity ranging between $1.5 \%$ and $3.52 \%$. The average permeability is $0.0746 \times 10^{-3} \mu^{2}$. The rock matrix porosity and permeability are relatively low, and the main reservoir space is the fracture-cavity type.

Compared with the measured reservoir properties data in the Weiyuan-Ziyang area, it is shown that among the typical 
structures of the Sichuan Basin, the matrix porosity of the Sinian Dengying Formation is optimal in central Sichuan, followed by the Weiyuan structure, Ziyang gas-bearing structure, and Dingshan structure in southeast Sichuan (Liu et al, 2007). Although the matrix porosity and permeability are lower in the reservoirs, the Sinian fractures and solution holes are developed, leading to a set of qualified deep reservoirs (Dai and Wang, 1999).

For the Sinian gas reservoirs in the Sichuan Basin, not only can the Cambrian Qiongzhusi Formation (Jiulaodong Formation) be considered to be good source rocks. It also provides favorable sealing conditions for the Sinian reservoirs. Cambrian strata with a thickness greater than $1,000 \mathrm{~m}$ are distributed along the edges of the basin, while the strata are thinner in the central basin, with a thickness of 600-1,000 m. According to an analysis of the black shale at the Cambrian bottom using the mercury-injection method, the shale pores have an extremely small throat, with a general size of less than $0.0018-0.0184 \mu \mathrm{m}$ (among 106 samples) and a high sealing capacity (Xu et al, 2002). For example, the sealing index of the Cambrian cap rocks is $2.74 \times 10^{9} \mathrm{~m} \cdot \mathrm{s}^{-1}$ in the Weiyuan gas field, with a higher natural gas accumulation efficiency (Lü et al, 2005). In addition, the widely developed Cambrian gypsum layers also provide a favorable seal for hydrocarbon accumulation in the Sinian Dengying Formation (Jin et al, 2006). The Mid-Upper Cambrian, Ordovician and Silurian shale, Permian mudstone, and Triassic and Jurassic red sandstone, taken as regional cap rocks in the Sinian reservoirs, provide indirect sealing conditions for Sinian gas reservoirs.

\section{Formation and evolution of Sinian reservoirs}

\subsection{Thermal history of source rocks constrained by apatite fission track}

Because the Sinian strata in the Sichuan Basin have a multi-stage tectonic evolutionary history, ambiguity exists in the use of vitrinite reflectance as a geothermometer for reconstructing the thermal history. The fission-track geothermometer method offers a good solution to the above problem. Gleadow and Brown (2000) showed that different evolutionary paths of thermal history (with different time to reach maximum temperature) resulted in different distribution histograms of apatite track length (the average length might be equivalent for possible tracks). Therefore, the apatite fission track method can be used to determine an accurate subsidence-uplift history and the temperature experienced by a sample, in order to provide a detailed geological history model for the Easy $\% R_{\mathrm{o}}$ chemical kinetic model. It was found in the studies that the Sichuan Basin was formed in the uplift and denudation from the late Yanshan movement, resulting in an important influence on the thermal history of the Cambrian source rocks, as well as the final setting and positioning of the Sinian reservoirs. The apatite fission track method is able to accurately reconstruct the late uplift and denudation process, providing better constraints for the thermal history of the Cambrian source rocks in the Sichuan Basin.
The sampling and analysis of apatite samples were carried out on the surface and subsurface of typical structures in the Sichuan Basin. Results are shown in Table 1. Based on the experimental annealing model, measurement parameters such as the grain age and track length can be applied to simulating the thermal history of an apatite grain. The AFTSolve software was mainly used for simulating the thermal history in this study, where the simulation results passed the GOF and K-S tests, indicating that they were reliable (Ketcham et al, 2000; Xu et al, 2006).

The Anpingdian-Gaoshiti, Weiyuan, and Dingshan structures in Southeast Sichuan experienced almost the same history of initial burial and later uplift (Fig. 2). Central Sichuan was in a sedimentary burial stage until $60 \mathrm{Ma}$, which was followed by an uplift stage. According to the simulated $T$ - $t$ paths, the denuded strata in Mo 24 well were 2,030 m in thickness, and those in Mo 58 well were approximately 1,743 $\mathrm{m}$ thick.

The simulation results for 22 apatite samples in the weiyuan area reflect the subsidence-uplift history of the Weiyuan structure since $100 \mathrm{Ma}$ (Fig. 2). Samples from different positions in the Weiyuan structure reflected different uplift processes. Samples WS47 and WS43 reflected that both the wings of the Weiyuan Anticline began to uplift at $50 \mathrm{Ma}$, and the total amplitude of the uplift and denudation was 3,980 $\mathrm{m}$. Sample WS25, which came from near the core in the axis of the Weiyuan Anticline, began to uplift at $45 \mathrm{Ma}$ and the total amplitude of its uplift and denudation was $4,000 \mathrm{~m}$.

The temperature vs. time (T-t paths) of the Dingshan 1 well in the Dingshan structure (Fig. 2), Southeast Sichuan, showed that the period between 82.5 Ma and 72.1 Ma was a rapid uplift stage, when approximately 1,100-m-thick strata were denuded. The period between 72.1 Ma and 31.2 Ma was a slow uplift stage, when approximately 625-m-thick strata were denuded. The period between 31.2 Ma and 20.8 Ma was an abrupt uplift stage, when approximately 710-m-thick strata were denuded. The period between $20.8 \mathrm{Ma}$ and 10.7 Ma was a relatively stable stage, when approximately $185-\mathrm{m}$-thick strata were denuded. The period from 10.7 Ma to the present is a sharp uplift stage, during which the total thickness of denuded strata was around $3,190 \mathrm{~m}$ above the sampling point. The simulation results for surface samples around the Dingshan 1 well (DT8, DT6, ADX4, DT2) showed that $T-t$ paths were similar to those of samples from the Dingshan 1 well. All the simulation results for the samples from the three typical structures reveal that the Central and Southeast Sichuan region has always been in an uplift stage since the Late Cretaceous. The rapid uplift occurred due to the late Himalayan movement, with differences in the uplift rates and amplitudes.

Constrained by the above apatite fission track data, the subsidence-uplift and denudation history of the typical structures in the Sichuan Basin was obtained. Based on the individual layer data from drilling, lithology, and other data, the Easy $\% R_{\mathrm{o}}$ chemical kinetic model (Sweeney and Burnham, 1990) was applied to acquire the thermal history of the Cambrian source rocks in wells Anping 1, Wei 118, and Dingshan 1 (Figs. 3, 4, and 5, respectively). 
Table 1 Analysis results for apatite fission track in typical structures, Sichuan Basin

\begin{tabular}{|c|c|c|c|c|c|c|c|c|c|c|}
\hline $\begin{array}{l}\text { Sample No./ } \\
\text { Well No. }\end{array}$ & Lithology / Formation & $\begin{array}{l}\text { Sample depth/ } \\
\text { elevation, } \mathrm{m}\end{array}$ & $\begin{array}{l}\text { Number } \\
\text { of grains }\end{array}$ & $\begin{array}{c}\rho_{\mathrm{s}} \\
10^{5} \cdot \mathrm{cm}^{-2}\end{array}$ & $\begin{array}{c}\rho_{\mathrm{i}} \\
10^{5} \cdot \mathrm{cm}^{-2}\end{array}$ & $\begin{array}{c}\rho_{\mathrm{d}} \\
10^{5} \cdot \mathrm{cm}^{-2}\end{array}$ & $\begin{array}{c}P\left(\chi^{2}\right) \\
\%\end{array}$ & $\begin{array}{c}\text { Central } \\
\text { age, Ma } \\
( \pm 1 \sigma)\end{array}$ & $\begin{array}{c}\text { Pooled } \\
\text { age, Ma } \\
( \pm 1 \sigma)\end{array}$ & $L, \mu \mathrm{m}$ \\
\hline $\begin{array}{c}\text { M24-1/ } \\
\text { Mo24 Well }\end{array}$ & Sandstone / Xujiahe Fm $\left(\mathrm{T}_{3} \mathrm{x}^{4}\right)$ & 2021.6 & 21 & 0.865 & 18.236 & 13.415 & 39.9 & $12 \pm 1$ & $12 \pm 1$ & $11.4 \pm 2.5$ \\
\hline $\begin{array}{c}\text { M24-2/ } \\
\text { Mo24 Well }\end{array}$ & Sandstone / Xujiahe Fm $\left(\mathrm{T}_{3} \mathrm{x}^{2}\right)$ & 2239.0 & 21 & 0.735 & 15.450 & 13.605 & 63.4 & $12 \pm 1$ & $12 \pm 1$ & $10.8 \pm 2.1$ \\
\hline $\begin{array}{c}\text { M58/ } \\
\text { Mo58 Well }\end{array}$ & Sandstone / Xujiahe Fm $\left(\mathrm{T}_{3} \mathrm{x}^{2}\right)$ & 2141.0 & 17 & 0.442 & 12.289 & 13.794 & 52.7 & $10 \pm 1$ & $9 \pm 1$ & $11.8 \pm 2.2$ \\
\hline WS30 & Sandstone / Shaximiao Fm $\left(\mathrm{J}_{2} \mathrm{~s}\right)$ & 437 & 26 & 3.051 & 26.058 & 17.083 & 98.1 & $37 \pm 3$ & $37 \pm 3$ & $12.9 \pm 1.8$ \\
\hline WS40 & Sandstone / Xujiahe Fm $\left(\mathrm{T}_{3} \mathrm{x}\right)$ & 471 & 27 & 2.116 & 14.582 & 17.298 & 7.3 & $46 \pm 5$ & $47 \pm 4$ & $12.4 \pm 2.1$ \\
\hline WS43 & Sandstone / Xujiahe Fm $\left(\mathrm{T}_{3} \mathrm{x}\right)$ & 592 & 21 & 0.967 & 10.837 & 17.009 & 75.5 & $28 \pm 2$ & $28 \pm 2$ & $13.4 \pm 1.5$ \\
\hline WS70 & Sandstone / Xujiahe Fm $\left(\mathrm{T}_{3} \mathrm{x}\right)$ & 436 & 12 & 1.823 & 14.379 & 17.305 & 57.6 & $41 \pm 5$ & $41 \pm 5$ & $13.2 \pm 1.7$ \\
\hline WS15 & Sandstone / Xujiahe Fm $\left(\mathrm{T}_{3} \mathrm{x}\right)$ & 595 & 20 & 1.118 & 12.889 & 17.082 & 71.5 & $28 \pm 2$ & $28 \pm 2$ & $13.1 \pm 1.9$ \\
\hline WS25 & Sandstone / Xujiahe Fm $\left(\mathrm{T}_{3} \mathrm{x}\right)$ & 642 & 21 & 1.177 & 14.015 & 17.157 & 94.5 & $27 \pm 2$ & $27 \pm 2$ & $12.6 \pm 2.4$ \\
\hline WS46 & Sandstone / Shaximiao Fm $\left(\mathrm{J}_{2} \mathrm{~s}\right)$ & 360 & 23 & 1.412 & 10.575 & 17.010 & 0.5 & $42 \pm 4$ & $43 \pm 3$ & $12.3 \pm 2.1$ \\
\hline WS47 & Sandstone / Shaximiao Fm $\left(\mathrm{J}_{2} \mathrm{~s}\right)$ & 369 & 26 & 1.045 & 9.901 & 17.527 & 66.8 & $35 \pm 3$ & $35 \pm 3$ & $12.2 \pm 2.3$ \\
\hline DSA & Sandstone / Longtan Fm $\left(\mathrm{P}_{2} 1\right)$ & 380 & 26 & 2.311 & 10.860 & 13.984 & 5.4 & $52 \pm 5$ & $56 \pm 5$ & $11.9 \pm 2.5$ \\
\hline DT8 & Sandstone / Penglaizhen Fm $\left(\mathrm{J}_{3} \mathrm{p}\right)$ & 1098 & 22 & 1.692 & 9.208 & 15.120 & 68.2 & $52 \pm 4$ & $52 \pm 4$ & $12.0 \pm 2.7$ \\
\hline DT6 & Sandstone / Suining Fm $\left(\mathrm{J}_{3} \mathrm{sn}\right)$ & 952 & 26 & 2.996 & 15.827 & 15.688 & 42.2 & $52 \pm 5$ & $55 \pm 5$ & $11.7 \pm 2.8$ \\
\hline $\mathrm{ADX} 4$ & Sandstone / Shaximiao Fm $\left(\mathrm{J}_{2} \mathrm{~s}\right)$ & 904 & 26 & 1.637 & 10.233 & 16.067 & 99.9 & $48 \pm 3$ & $48 \pm 3$ & $11.8 \pm 2.9$ \\
\hline DT2 & Sandstone / Xujiahe Fm $\left(\mathrm{T}_{3} \mathrm{x}\right)$ & 1050 & 25 & 2.368 & 12.967 & 15.309 & 35.8 & $49 \pm 5$ & $52 \pm 5$ & $12.0 \pm 2.4$ \\
\hline
\end{tabular}

Notes: $\rho_{\mathrm{s}}$, spontaneous fission-track density; $\rho_{\mathrm{i}}$, induced fission-track density; $\rho_{\mathrm{d}}$, standard fission-track density; $P\left(\chi^{2}\right)$, probability of inferred Poissonian distribution of single grain age; $L$, track length

\subsection{Formation and evolution of Sinian reservoirs in typical structures}

\subsubsection{Anpingdian structure}

The thermal evolutionary history of the source rocks in the Cambrian Qiongzhusi Formation, in well Anping 1, Central Sichuan (Fig. 3) showed the following results. Hydrocarbon generation occurred in the Cambrian Jiulaodong Formation source rocks in the Late Ordovician-Late Silurian (the $R_{\mathrm{o}}$ value was greater than $0.5 \%$ ). This period was considered to be the initial hydrocarbon generation stage for the Cambrian source rocks, as well as the crude oil charge stage.

A specific trap morphology existed in wells Anping 1 and Gaoke 1 of the Anpingdian-Gaoshiti structure, which enabled the capture of crude oil generated in the Cambrian source rocks. This period was considered to be the formation stage for early paleo-oil pools (Fig. 6). During the end of the Silurian sedimentary period, the strata were uplifted and denuded as a result of the Caledonian Movement (Liu et al, 2010). Early paleo-oil pools were destroyed, and this process is recorded by the chromatographic features of the saturated hydrocarbon of the Sinian reservoir bitumen in the Anpingdian and Gaoshiti structures (Fig. 7).

The Cambrian source rocks experienced continuous burial in the Early Permian. Until the Mid-Late Permian, the $R_{\mathrm{o}}$ value of the Cambrian source rocks was $0.7 \%$ in Central
Sichuan, when a large amount of oil generation occurred (Fig. 3, Fig. 6). In the Early-Mid Triassic, the Cambrian hydrocarbon sources experienced a peak in oil generation ( $R_{\mathrm{o}}$ of the source rocks was approximately $1.0 \%$ ). The wet gas generation stage began in the Early Jurassic $\left(R_{\mathrm{o}}\right.$ was approximately $1.3 \%$ ). In the Early-Middle Jurassic, the Sinian reservoirs were mainly charged by wet gas generated in the Cambrian source rocks $\left(R_{\mathrm{o}}\right.$ of the source rocks was $1.3 \%-2.0 \%)$. In the late Mid-Jurassic, a large amount of dry gas began to be generated in the source rocks $\left(R_{0}\right.$ of the source rocks was $2.0 \%$ ). In the early Mid-Jurassic, the Sinian reservoirs had a roof buried at a depth of around 4,500 m and a formation temperature of $160{ }^{\circ} \mathrm{C}$, where the cracking of oil to gas occurred (Schenk et al, 1997), leading to the formation of pyrolysis bitumen. Until the Mid-Late Jurassic, the roof of the Sinian reservoirs was buried at a depth of $6,200 \mathrm{~m}$, a paleo-temperature of $215^{\circ} \mathrm{C}$, and the maximum amount of oil cracking to gas was obtained. Because of the multi-stage hydrocarbon generation of the Cambrian source rocks, a multi-stage hydrocarbon charge exists in the Sinian reservoirs. The homogenization temperatures of the fluid inclusions in the Sinian reservoirs are mainly concentrated in the ranges of $130-170{ }^{\circ} \mathrm{C}, 210-220^{\circ} \mathrm{C}$, and $230-260^{\circ} \mathrm{C}$. This indicates that at least three stages of fluid charge existed in the reservoirs, i.e., the late Triassic-Early Jurassic, Mid-Late Jurassic, and Mid-Late Cretaceous (Yuan, 2008). 

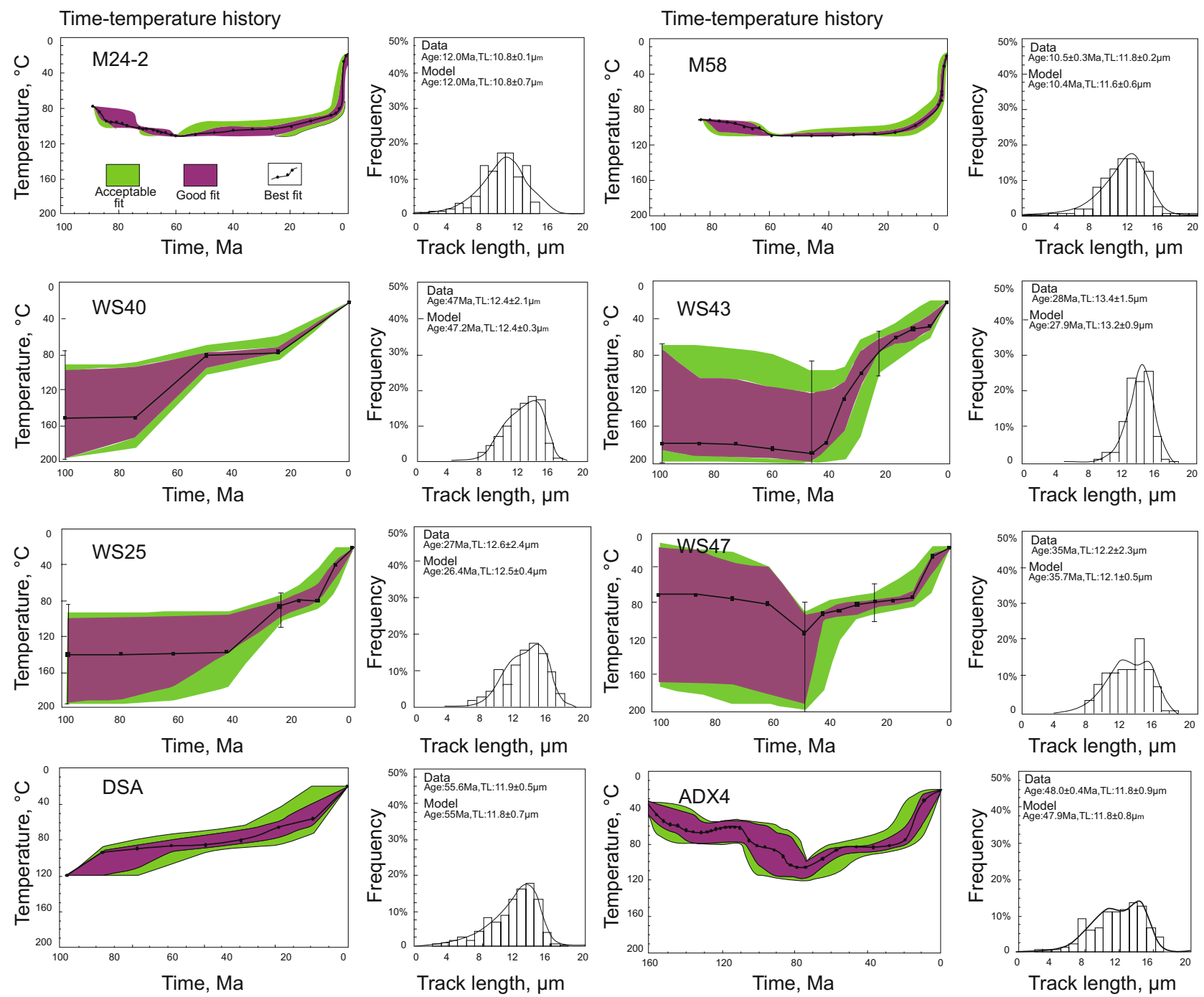

Fig. 2 Simulated results of apatite fission track data for typical structures, Sichuan Basin

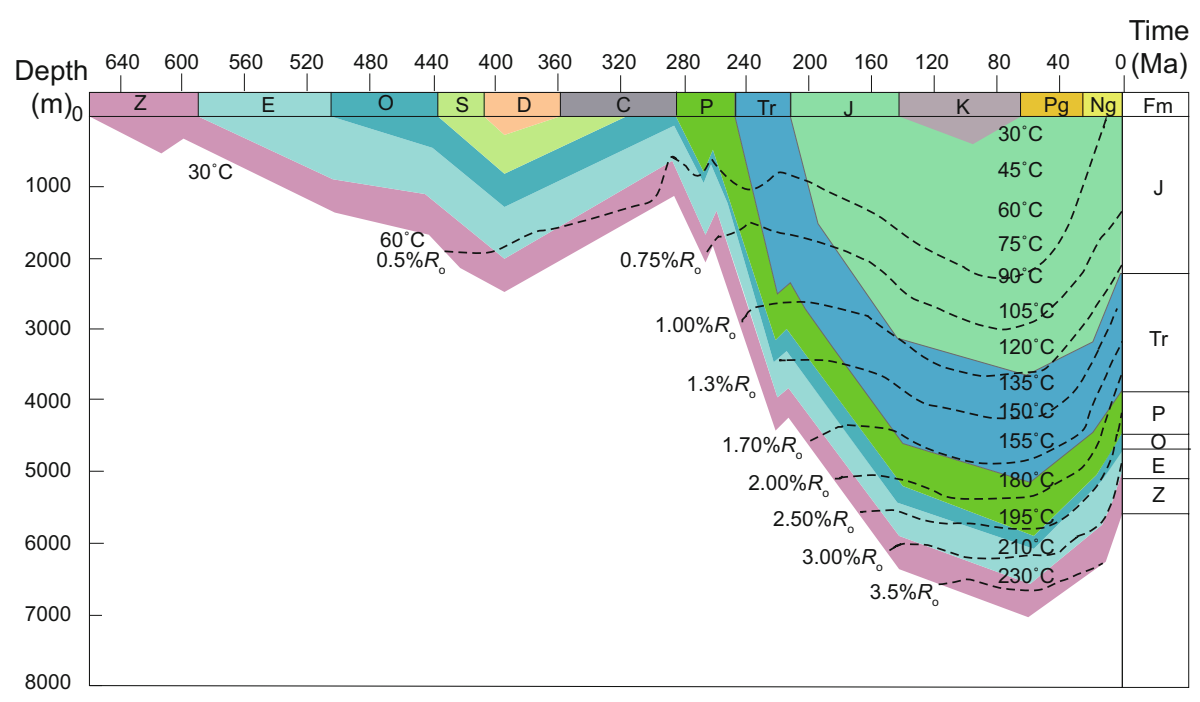

Fig. 3 Thermal history of well Anping 1, Anpingdian-Gaoshiti structural belt, Central Sichuan

The Anpingdian-Gaoshiti structure began to uplift and denudate since the Late Cretaceous, and very few changes occurred in the trap morphology during the uplift process. However, because of the reduction in temperature and pressure in the uplift process, natural gas that was earlier dissolved in the formation water exsolved. Because there is no dissolved gas in the current gas pools, it has been speculated that the solubility changed by $30-50 \mathrm{~m}^{3} / \mathrm{m}^{3}$ in the exsolution 


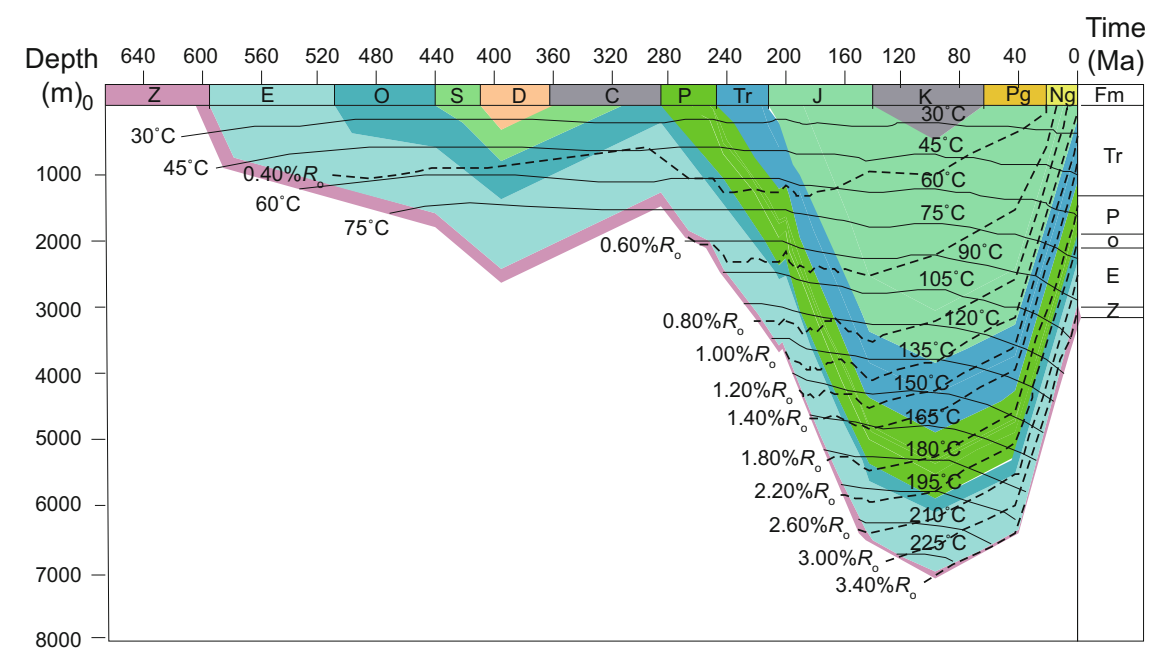

Fig. 4 Thermal history of well Wei 118, Weiyuan structure, South Sichuan

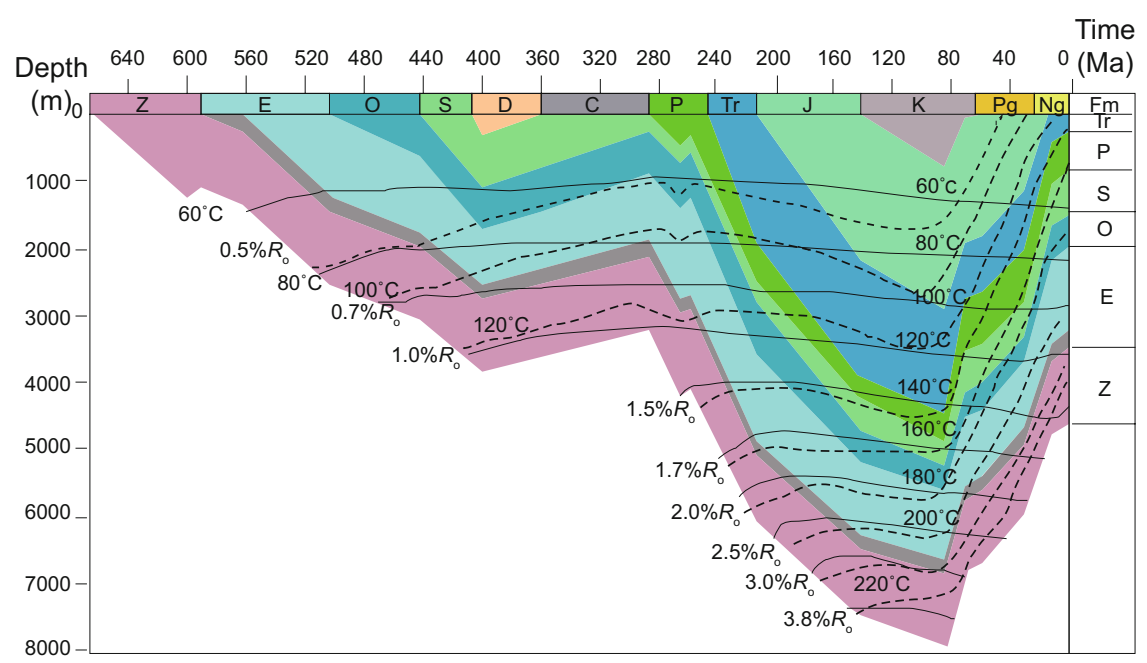

Fig. 5 Thermal history of well Dingshan 1, Dingshan structure, Southeast Sichuan

process (a detailed discussion is presented in section 4.3). The current Sinian gas pools are only gas-bearing structures, where a majority of the natural gas may have migrated to the Weiyuan and Ziyang areas with a higher tectonic position after the uplift and exsolution (Fig. 3, Fig. 6).

\subsubsection{Weiyuan structure}

The Weiyuan gas field and Ziyang gas-bearing area entered a subsidence stage in the Cambrian-Late Silurian. A Leshan-Longnüsi paleo-uplift occurred, and the Ziyang and Weiyuan areas were located in higher positions (Fig. 4, Fig. $8)$. The Lower Cambrian source rocks of south and southeast Sichuan were mature with hydrocarbon expulsion. The paleouplift provided a favorable area for hydrocarbon migration, leading to the formation of paleo-oil pools in the WeiyuanZiyang area (Cui et al, 2008). Similar to the paleo-oil pools in the Anpingdian-Gaoshiti structure, these paleo-oil pools were damaged slightly at the end of the Silurian and biodegraded bitumen was formed (Fig. 7).

Overall subsidence occurred in the Ziyang and Weiyuan areas since the Permian, and the Ziyang-Weiyuan paleo- trap was further developed. The Weiyuan area was located on the south slope of the Ziyang paleo-trap. A large amount of hydrocarbon generation occurred in the Cambrian source rocks of the Weiyuan area (Weiyuan 118 well) $\left(R_{\mathrm{o}}\right.$ was approximately $0.65 \%$ ). In the Permian-Triassic, the hydrocarbons were captured by the Ziyang-Weiyuan paleotrap, leading to the formation of the late paleo-reservoirs (Fig. 3). In the Early-Mid Jurassic, the Cambrian source rocks of the Weiyuan structure evolved to the stage of condensate and wet gas formation $\left(R_{\mathrm{o}}\right.$ was approximately $\left.1.3 \%\right)$. Until the late Mid-Jurassic, a large amount of dry gas began to be generated in the Cambrian source rocks ( $R_{\mathrm{o}}$ was approximately $2.0 \%$ ). However, the Sinian reservoirs had a roof buried at a depth of $4,700 \mathrm{~m}$ and a paleo-temperature of up to $160{ }^{\circ} \mathrm{C}$ since the Early-Mid Jurassic. The cracking of oil to gas occurred in large quantities until the Late Cretaceous, which was generated in the paleo-reservoirs. The kerogen-cracking gas and oil-cracking gas formed almost at the same time, and they mixed with each other. Through an analysis of apatite fission track data (Table 1, Fig. 4) and inclusion temperature 
measurement data, it was shown (Tang et al, 2005) that the Sinian reservoirs had a roof buried at a depth greater than $7,000 \mathrm{~m}$ and a paleo-temperature above $210^{\circ} \mathrm{C}$. Crude oil in the paleo-reservoirs was almost completely cracked to natural gas, leading to the formation of bitumen. Few changes occurred to the morphology and location of the ZiyangWeiyuan paleo-trap during this period.

The characteristics and homogenization temperatures of the organic mineral inclusions that filled the Sinian pores, holes, and fractures in the Weiyuan-Ziyang area, Southwest Sichuan, during different stages showed that at least three phases of hydrocarbon migration occurred in this area, and the paleo-temperatures range $110-130{ }^{\circ} \mathrm{C}, 150-160$ ${ }^{\circ} \mathrm{C}$, and $170-230{ }^{\circ} \mathrm{C}$, respectively (Tang et al, 2003; 2005). According to the reconstructed evolutionary history of the paleo-temperature, Stage-I hydrocarbon migration occurred

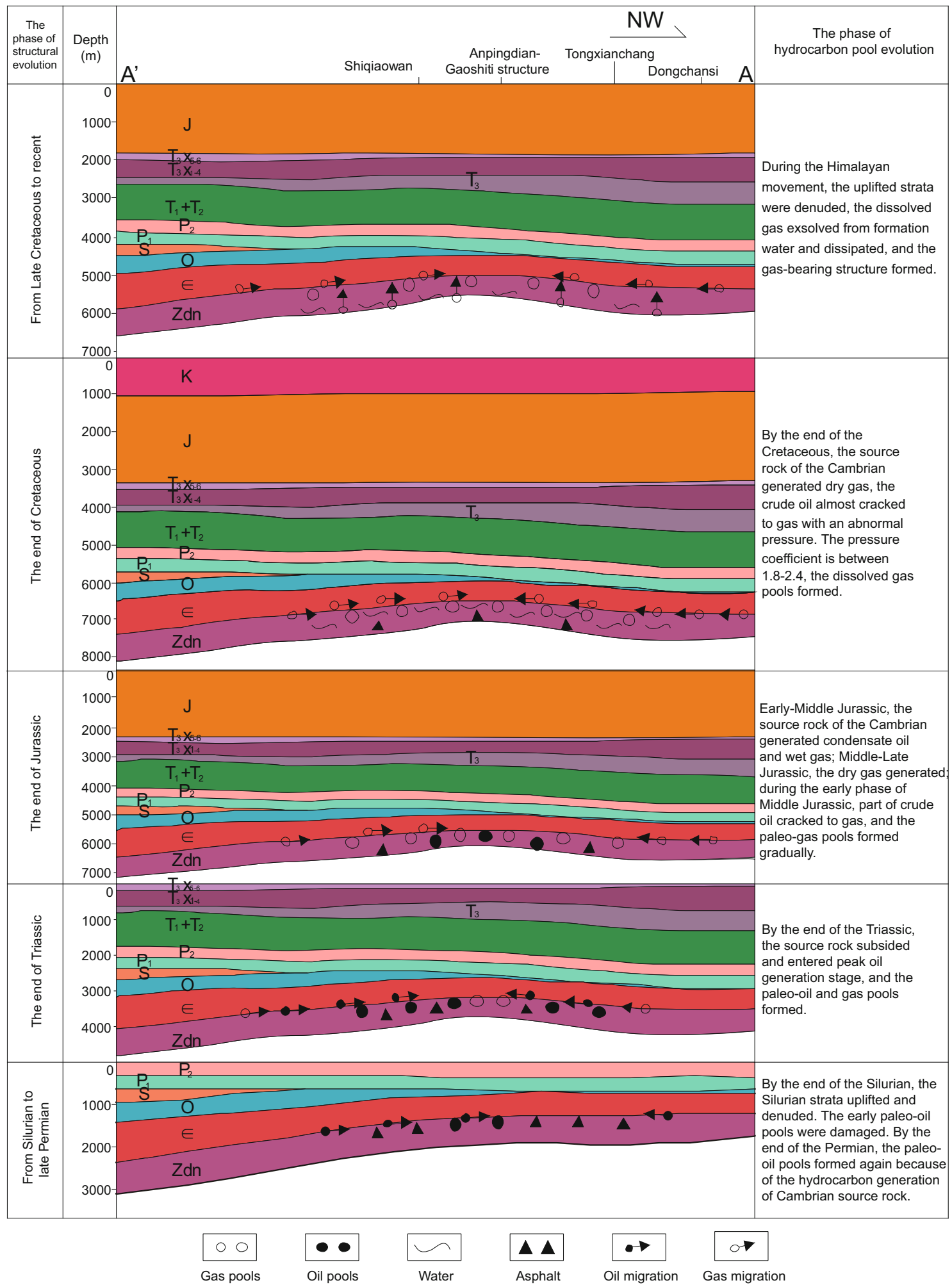

Fig. 6 Evolution of oil and gas pools, Anpingdian-Gaoshiti structure 
in the Indo-Chinese Epoch as the oil-generation peak of the source rocks. Stage-II hydrocarbon migration occurred in the Yanshanian, when some liquid hydrocarbons started to crack, and organic matter reached a high-maturity stage. Stage-III hydrocarbon migration occurred in the YanshanianHimalayan (Fig. 4, Fig. 8).

Himalayan tectonism played a decisive role in the formation of the Weiyuan gas field. The Weiyuan structure on the south slope of the Leshan-Longnüsi Paleo-uplift reached a structural high taking the place of Ziyang structure, and the final setting and positioning of the traps were established. A portion of the natural gas migrated from the Ziyang paleo-trap to the Weiyuan structure, and more natural gas was trapped in the Sinian trap of the Weiyuan structure (Dai and Wang, 1999; Liu et al, 2008b; Yuan et al, 2009). In addition, because of an uplift with great amplitude, the reduction of the temperature and pressure in the uplift process resulted in the exsolution of natural gas in the Sinian paleo dissolved-gas reservoirs of Weiyuan. The solubility in formation water was reduced from $7.57 \mathrm{~m}^{3} / \mathrm{m}^{3}$ before the Himalayan to the present value of 2.42 $\mathrm{m}^{3} / \mathrm{m}^{3}$. The exsolved dissolved-gas reserves were $493 \times 10^{8}$ $\mathrm{m}^{3}$, which is close to the current proven gas reserves of $400 \times$ $10^{8} \mathrm{~m}^{3}$ located in the Weiyuan gas field (Liu et al, 2000) (Fig. 4, Fig. 8).

\subsubsection{Dingshan structure}

Hydrocarbon generation occurred in the Cambrian source rocks of the Dingshan structure in the Early Silurian. The source rocks of the Cambrian Niutitang Formation had a buried depth of $2,100 \mathrm{~m}$, where oil generation began in organic matter $\left(R_{\mathrm{o}}\right.$ was approximately $\left.0.5 \%\right)$. Until the Late Silurian, the Cambrian source rocks generated oil in large amounts $\left(R_{\circ}\right.$ was $\left.0.7 \%\right)$, and the paleo-petroleum reservoirs formed. At the end of the Silurian, because of the Caledonian uplift, hydrocarbon generation stopped, and the paleoreservoirs were destroyed, because the strata were uplifted and denuded (Yuan, 2008) (Figs. 5, 7, and 9).

In the Permian, continuous burial occurred to the Cambrian source rocks with renewed hydrocarbon generation. In the Late Permian, the top of the Cambrian source rocks had an oil generation peak ( $R_{\mathrm{o}}$ was $\left.1.3 \%\right)$. During the EarlyMid Jurassic, the source rocks evolved to the dry gas stage $\left(R_{\mathrm{o}}\right.$ was $\left.2.0 \%\right)$. The roof of the Sinian reservoirs had a buried depth of approximately $4,650 \mathrm{~m}$ and a corresponding paleo-temperature of $160{ }^{\circ} \mathrm{C}$ in the Late Triassic-Early-Mid Jurassic, when gas cracked from previously charged oil in the reservoirs of the Sinian Dengying Formation $\left(Z_{2} d n\right)$. The early-charged oil in the paleo-reservoirs had become a major source of natural gas in this area. Until the Late Jurassic, the roof of the Sinian reservoirs had a buried depth of 6,700 $\mathrm{m}$ and a paleo-temperature of $210{ }^{\circ} \mathrm{C}$, when oil almost completely cracked to gas (Fig. 5). During the TriassicLate Jurassic, the traps of the Dingshan structure were in a successive development stage, with changes in the trap morphology (Fig. 9).
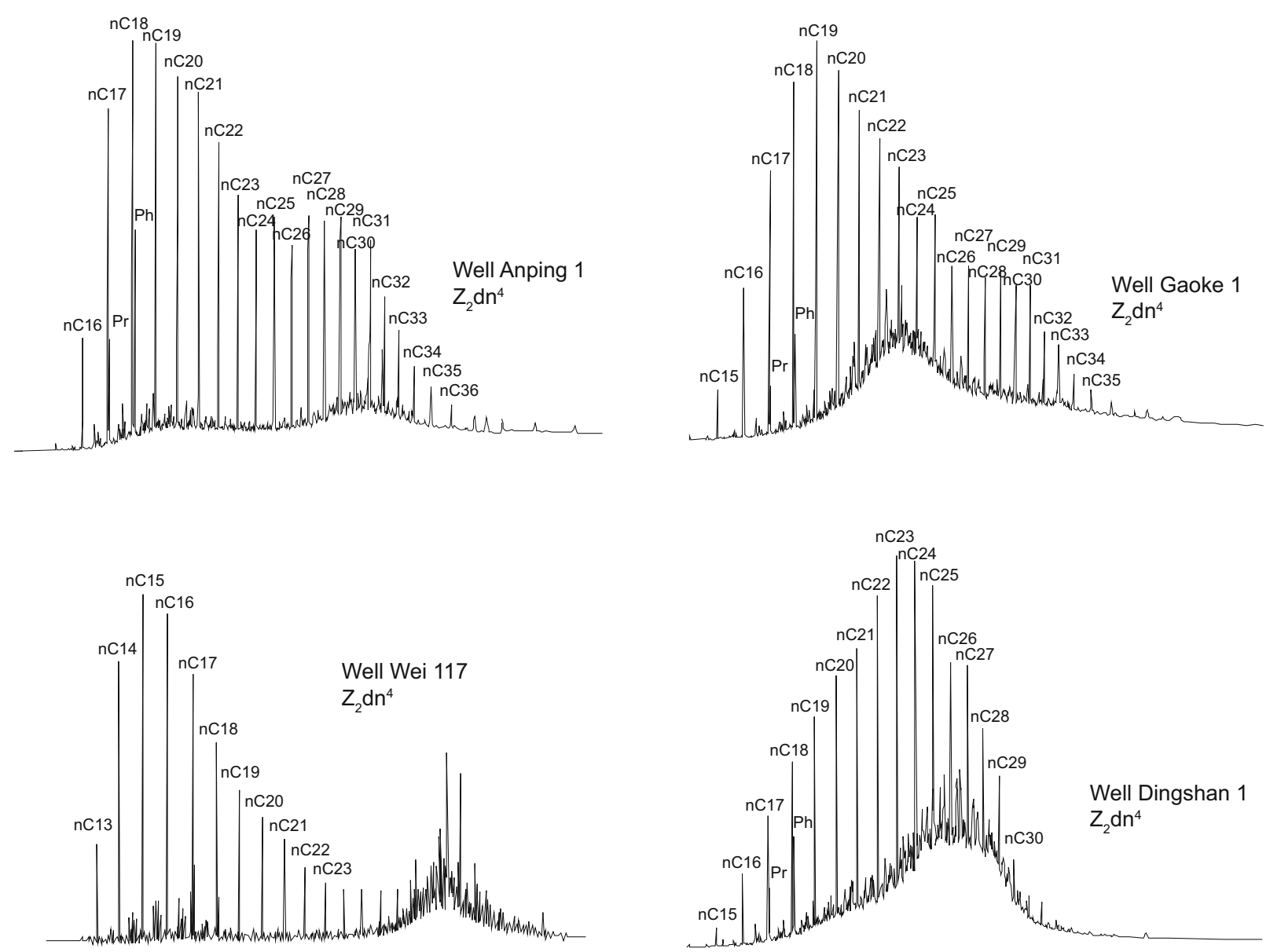

Fig. 7 Saturated hydrocarbon chromatograms of bitumen samples in Sinian reservoirs of typical structures, Sichuan Basin 
Since $82 \mathrm{Ma}$, uplifts with great amplitude occurred in the Dingshan structure in three phases, i.e., rapid uplift, slow uplift, and rapid uplift, where the tectonism was significantly stronger than that in central and southwest Sichuan. As a result, the Permian strata were exposed in well Dingshan 1. Because of the uplift, the temperature of the surrounding rocks decreased, leading to a break in the balanced system and the exsolution of natural gas dissolved in water. Because of the strong Himalayan tectonism, faults were well developed in the Dingshan structure, even connected to the ground surface. These faults and fractures constituted a rapid dispersive channel for natural gas, which completely destroyed the natural gas reservoirs in the Dingshan structure (Fig. 5, Fig. 9). The water type in the present Sinian formation was $\mathrm{NaHCO}_{3}$, indicating that the Sinian reservoirs in Dingshan 1 well were in an open system for a long term.

\subsection{Exsolution effects of dissolved gas on hydrocarbon accumulation in Sinian reservoirs}

It should be noted that during the formation and evolution

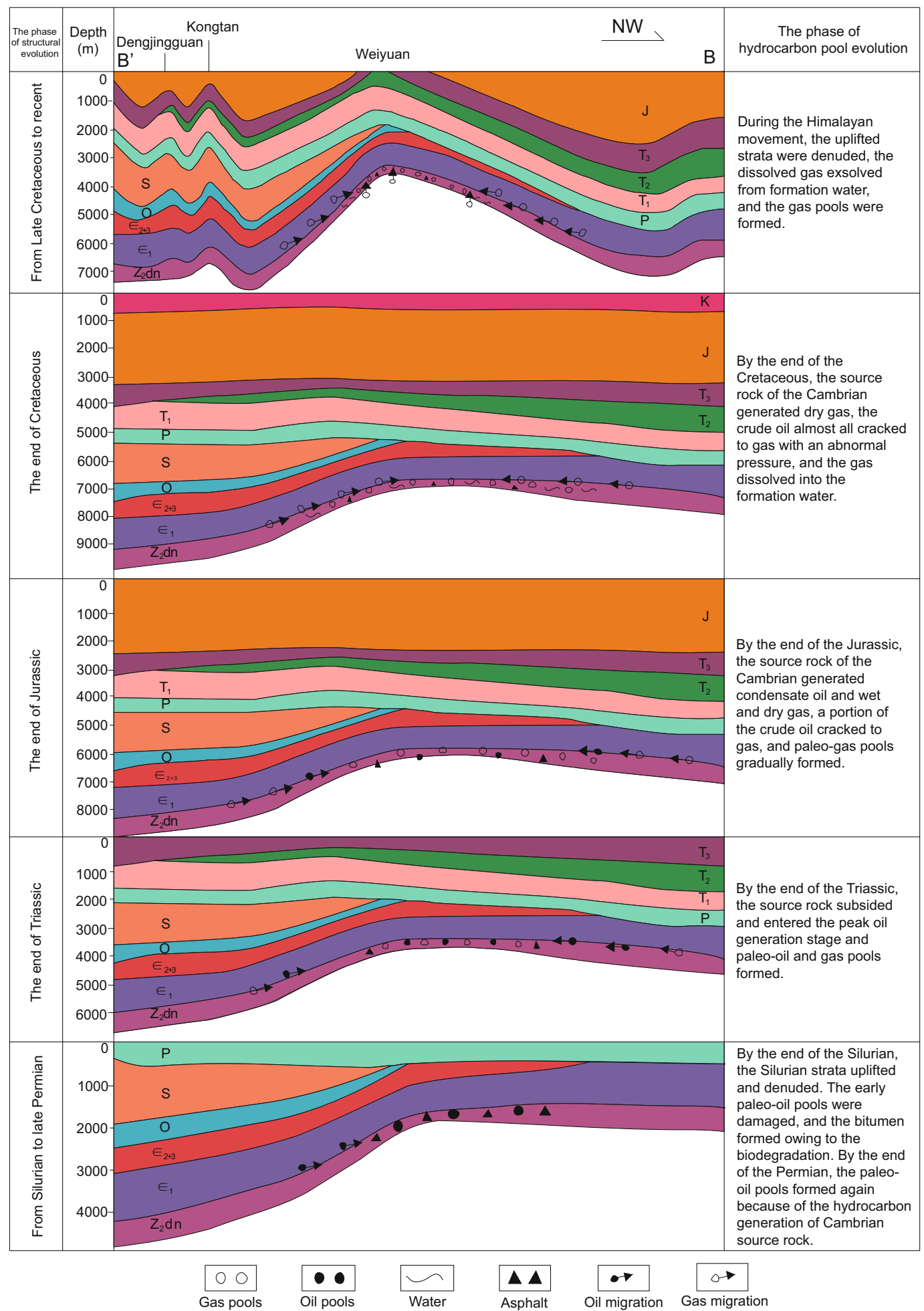

Fig. 8 Evolution of oil and gas pools, Weiyuan structure 
process of the Sinian reservoirs, the formation of dissolvedgas pools and Himalayan tectonism were closely related to the formation of the present gas reservoirs. The Sichuan Basin experienced a process of continuous burial and hightemperature evolution during the Permian-Late Cretaceous. In the Early-Mid Jurassic-Late Cretaceous, the crude oil in the Sinian reservoirs was gradually cracked to gas, and this process led to volume expansion and abnormally high pressure in the Sinian paleo-reservoirs. Under the high temperature and high pressure, a large amount of natural gas from kerogen and the cracking of oil dissolved in formation water led to the generation of dissolved-gas accumulations. The dissolved-gas events may be universal in the Sinian geological history of the Sichuan Basin. The existing evidences of paleo dissolved-gas pools were discovered by the authors in the fluid inclusions of the Sinian drill cores. The organic inclusions in the quartz and calcite at the last charge stage of the Sinian reservoirs in well Anping 1, Central

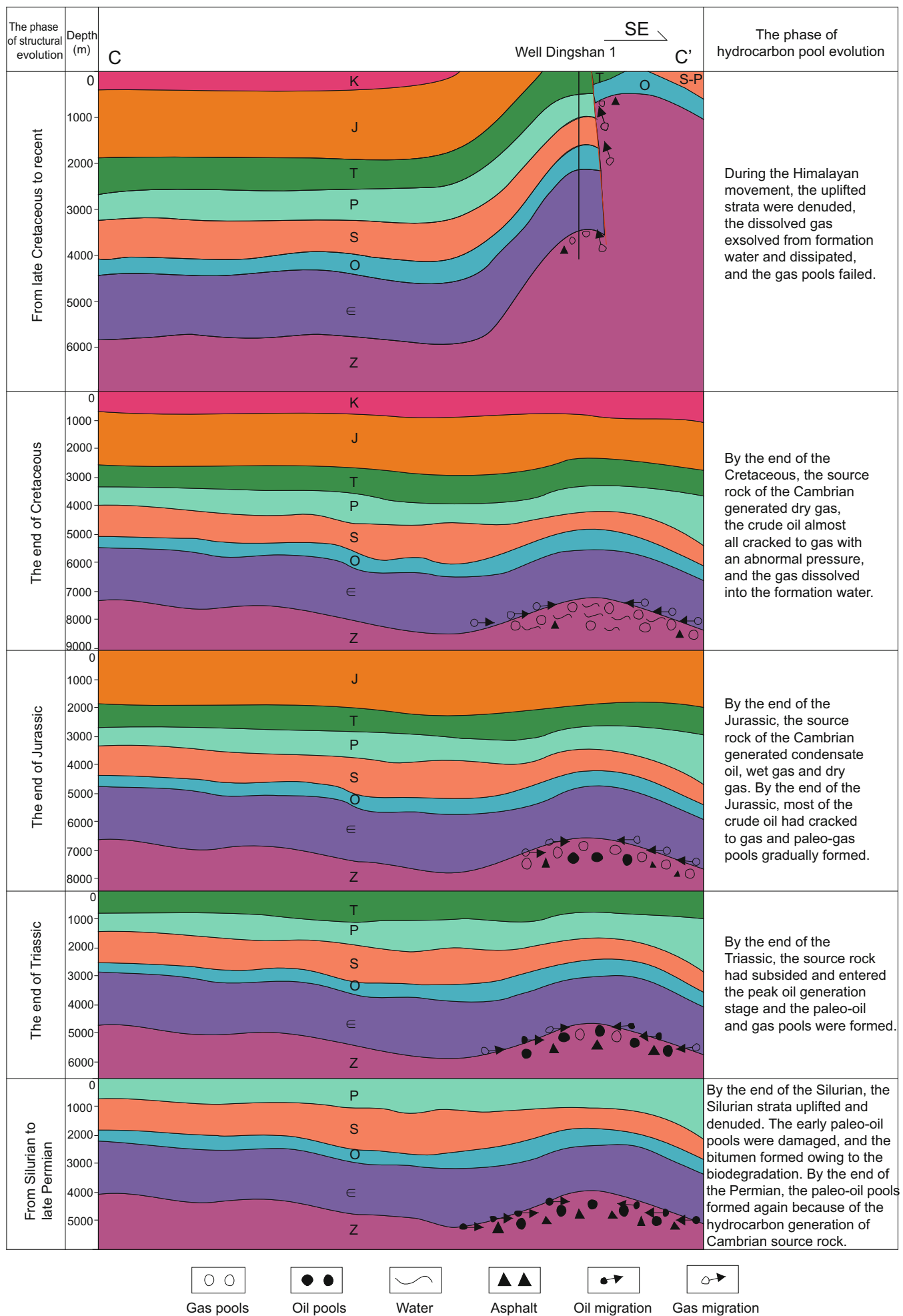

Fig. 9 Evolution of oil and gas pools, Dingshan structure 
Sichuan Basin, mainly consisted of dissolved methane inclusions, which was also proven by the peak intensity and area distribution of laser Raman spectra. PVTsim simulation technology was used to obtain the paleo-pressure of the fluid inclusions (Yuan et al, 2008). Corresponding to the peak temperature of $260-290{ }^{\circ} \mathrm{C}$ for the Sinian inclusions in Central Sichuan, the minimum fluid pressure was 1,200-1,600 bar and the paleo-pore fluid pressure coefficient was 1.842.40 , leading to overpressured fluids. The conversion of oil to gas resulted in a volume expansion, which was the main factor for the formation of abnormally high pressure. Under these temperature and pressure conditions, around $50-90 \mathrm{~m}^{3}$ dissolved-gas existed in every $1 \mathrm{~m}^{3}$ water (Price, 1979). As estimated by the same method, approximately $10-30 \mathrm{~m}^{3}$ gas dissolved in every $1 \mathrm{~m}^{3}$ water in the Cambrian reservoirs, Southeast Sichuan (Yuan, 2008). Because no core samples from the Weiyuan area are available, no direct evidence could be given to verify the existence of dissolved-gas reservoirs in the Sinian Weiyuan gas field. However, it was proven in previous studies that the pressure coefficient could reach 2.05 in the cracking of oil to gas in the Sinian Weiyuan gas field (Sun et al, 2007), and dissolved-gas events occurred (Yuan, 2008; Yuan et al, 2009). After the formation of the dissolvedgas reservoirs, the formation water in the reservoirs provided the natural gas with its preservative carrier. Natural gas always existed in a water soluble form until the occurrence of the uplift from the Himalayan movement, which could effectively prevent the destruction of the gas pools caused by the tectonic movement and other factors during this period, and this provided the safeguard for the final setting of the Sinian gas reservoirs.

Influenced by the Himalayan tectonism, an overall uplift occurred in the Sichuan Basin, except for the West Sichuan Depression, since the Late Cretaceous. Because of the decreased temperature of the early-formed dissolved gas pools, the original balance of gas reservoirs was broken, and exsolution of a large amount of natural gas occurred which had been dissolved in water, accompanied by the partial loss and transfer of natural gas. The establishment of the Sinian gas reservoirs was in their final setting. In fact, the previous research results also verify that the formation of some giant gas fields was related to the exsolution and accumulation of previously dissolved-gas (Cramer et al, 2002; Littke et al, 1999; Qin et al, 2006; 2007; Li et al, 2003; Chen et al, 1997), including the Hetianhe gas field in the Tarim Basin and the Urengoy gas field in the West Siberia Basin.

The formation and evolution of the Sinian reservoirs in the typical structures of the Sichuan Basin mainly underwent the following stages: 1) Paleo-oil pool formation and destruction in the late Silurian; 2) Renewed hydrocarbon generation of the Cambrian source rocks and hydrocarbon recharge in the Early Permian-Early-Mid Triassic; 3) Cracking of oil to gas and dissolved-gas formation in the Late Triassic-MidLate Jurassic; 4) Phasic uplift, exsolution of natural gas, final setting and positioning of gas reservoirs from the Late Cretaceous until now. However, because of the differences in the amplitudes of the uplift, tectonic deformation strength and different trap conditions for various typical structures, large gas fields, residual gas reservoirs, and gas-bearing structures were formed in the Weiyuan, Ziyang, and AnpingdianGaoshiti structural belts of Central Sichuan. Influenced by the strongest transformation and destruction, the Dingshan structure in Southeast Sichuan has almost been completely destroyed.

\section{Conclusions}

1) It has been proven in the analysis above that the source rocks of the Sinian reservoirs in the Sichuan Basin were the shales of the Lower Cambrian, which had a high abundance of organic matter, great thickness, and strong hydrocarbon generation capacity. However, the current proven level of Sinian hydrocarbon resources is low, and only the Weiyuan gas field has been found, which promises considerable exploration space and potential. Favorable conditions exist in the source-reservoir-seal assemblage of the Sinian traps, Sichuan Basin. As viewed from the development and evolution history of the traps in typical structures, traps were formed prior to the oil generation peak of the source rocks, which is beneficial for the accumulation and preservation of hydrocarbon.

2) The thermal evolutionary history of the Cambrian source rocks constrained by the apatite fission track data, as well as the trap evolutionary history of typical structures, revealed that Sinian natural gas pools underwent an evolutionary accumulation process, i.e., paleo-oil pools $\rightarrow$ paleo-gas pools $\rightarrow$ current-gas pools (adjusting and reforming). The exsolution of dissolved-gas caused by tectonic uplift played an important role in hydrocarbon accumulation since the Late Cretaceous. The formation of the Weiyuan gas field, Ziyang gas pools, and AnpingdianGaoshiti gas-bearing structure was closely related to the processes mentioned above.

3) The formation and evolution of the reservoirs showed that the early-existing reservoirs located in areas that were subjected to strong tectonic deformation and reformation were easily damaged (such as the Dingshan structure). However, the Leshan-Longnüsi Paleo-uplift area was less influenced by the later tectonism, with no strong deformation and no development of deep and large faults, which is beneficial for natural gas accumulation and preservation. This area shall be a target area for further exploration, and oil and gas exploration could have a breakthrough in this area.

\section{Acknowledgements}

This paper is funded by the National Key Basic Research Programs (973) "Deep hydrocarbon accumulation mechanism of China's marine carbonate strata" (2005CB422106) and "The structure evolution in middle and upper Yangtze region and multi-period hydrocarbon accumulation in lower Paleozoic" (2012CB214805).

\section{References}

Chen H H, Fu X M and Yang J M. Natural gases replenishment in the Ya13-1 Gas Field in the Ying-Qiong Basins, South China Sea. Acta Petrolei Sinica. 1997. 18(4): 32-37 (in Chinese)

Chen Z Q. Gas exploration in Sinian Dengying Formation, Sichuan 
Basin. China Petroleum Exploration. 2010. 15(4): 1-14 (in Chinese)

Cramer B, Schlömer S and Poelchau H S. Uplift-related hydrocarbon accumulations: The release of natural gas from groundwater. Geological Society, London, Special Publications. 2002. 196(1): 447-455

Cui H Y, Zhang L, Wei G Q, et al. Characteristics of the Sinian reservoir bitumen in Weiyuan-Ziyang areas of the Sichuan Basin and its significance. Petroleum Geology and Experiment. 2008. 30(5): 489493 (in Chinese)

Dai H M and Wang S Y. Formation characteristics of natural gas reservoirs and favorable exploration areas in the Sinian-Cambrian petroleum system of Sichuan Basin. Petroleum Exploration and Development. 1999. 26(5): 16-20 (in Chinese)

Gleadow A J W and Brown R W. Fission-track thermochronology and the long-term denudational response to tectonics. Geomorphology and Global Tectonics. 2000. 57-75

Jin Z J, Long S X, Zhou Y, et al. A study on the distribution of saline deposits in southern China. Oil and Gas Geology. 2006. 27(5): 571583 (in Chinese)

Ketcham R A, Donelick R A and Donelick M B. AFTSolve: A program for multi-kinetic modeling of apatite fission-track data. Geological Materials Research. 2000. 2(1): 1-32

Li M, Li Q, Zhang Q C, et al. Deep water-soluble natural gas at the thrust-uplift belt in the Kuche Foreland Basin. Natural Gas Geoscience. 2003. 14(5): 366-370 (in Chinese)

Littke R, Cramer B, Gerling P, et al. Gas generation and accumulation in the West Siberian Basin. AAPG Bulletin. 1999. 83(10): 1642-1665

Liu D L, Song Y and Xue A M. Structural Evolution and Natural Gas Accumulation Zone Comprehensive Study in the Sichuan Basin. Beijing: Petroleum Industry Press. 2000. 63 (in Chinese)

Liu S G, Li Z W, Sun W, et al. Basic geological features of superimposed basin and hydrocarbon accumulation in the Sichuan Basin, China. Chinese Journal of Geology. 2011. 46(1): 233-257 (in Chinese)

Liu S G, Ma Y S, Huang W M, et al. Densification process of the upper Sinian Dengying Formation, Sichuan Basin. Natural Gas Geoscience. 2007. 18(4): 485-496 (in Chinese)

Liu S G, Ma Y S, Sun W, et al. Studying on the differences of the Sinian natural gas pools between the Weiyuan Gas Field and Ziyang GasProne area, Sichuan Basin. Acta Geologica Sinica. 2008a. 82(3): 328-337 (in Chinese)

Liu S G, Sun W, Li Z W, et al. Tectonic uplifting and gas pool formation since the late Cretaceous Epoch, Sichuan Basin. Natural Gas Geoscience. 2008b. 19(3): 293-300 (in Chinese)

Liu S G, Zhang Z J, Huang W M, et al. Formation and destruction processes of upper Sinian oil-gas pools in the Dingshan-Lintanchang structural belt, southeast Sichuan Basin, China. Petroleum Science. 2010. 7(3): 289-301

Lü Y F, Fu G and Yu D. Comprehensive evaluation of sealing ability of cap rock in China's large and medium gas fields and their contribution to gas accumulation. Oil and Gas Geology. 2005. 26(6): 742-753 (in Chinese)
Price L C. Aqueous solubility of methane at elevated pressures and temperatures. AAPG Bulletin. 1979. 63(9): 1527-1533

Qin S F, Li M, Hu J F, et al. Implication to Kela 2 Gas Field from watersoluble gas accumulation in the Hetianhe Gas Field. Natural Gas Geoscience. 2007. 18(1): 45-49 (in Chinese)

Qin S F, Zou C N, Dai J X, et al. Water-soluble gas accumulation process of the Hetianhe gas field in the Tarim Basin, NW China. Petroleum Exploration and Development. 2006. 33(3): 282-288 (in Chinese)

Schenk H J, Di Primio R and Horsfield B. The conversion of oil into gas in petroleum reservoirs. Part 1: Comparative kinetic investigation of gas generation from crude oils of lacustrine, marine and fluviodeltaic origin by programmed-temperature closed-system pyrolysis. Organic Geochemistry. 1997. 26(7-8): 467-481

Sun W, Liu S G, Ma Y S, et al. Determination and quantitative simulation of gas pool formation processes of Sinian cracked gas in the Weiyuan - Ziyang area, Sichuan Basin. Acta Geologica Sinica. 2007. 81(8): 1153-1159 (in Chinese)

Sweeney J and Burnham A K. Evaluation of a simple model of vitrinite reflectance based on chemical kinetics. AAPG Bulletin. 1990. 74(10): 1559-1570

Tang J H, Zhang T W, Bao Z Y, et al. Fluid inclusion study and its application in oil geology of the Southwest Sichuan Basin. Geological Science and Technology Information. 2003. 22(4): 60-64 (in Chinese)

Tang J H, Zhang T W, Bao Z Y, et al. Application of organic inclusions in oil-gas migration of the Sichuan reservoir of Southwest Sichuan Basin. Earth Science- Journal of China University of Geosciences. 2005. 30(2): 228-232 (in Chinese)

Xu C H, Zhou Z Y, Van Den Haute P, et al. Apatite fission-track thermochronology of tectonic evolution in the Hefei Basin. Acta Petrolei Sinica. 2006. 27(6): 5-13 (in Chinese)

$\mathrm{Xu}$ S Q. Conditions of forming reservoirs in the Sinian-Cambrian of the Caledonian ancient uplift. Natural Gas Industry. 1999. 19(6): 7-10 (in Chinese)

Xu S Q, Hong H T and Li X. The characteristics and rules of hydrocarbon accumulation in the Sinian of the Sichuan Basin. Natural Gas Exploration and Development. 2002. 25(4): 1-5 (in Chinese)

Yuan H F. The mechanism of hydrocarbon accumulation, Sinian-Lower Palaeozoic, Sichuan Basin. Ph.D. Thesis. Chengdu University of Technology. 2008 (in Chinese)

Yuan H F, Xu G S, Liu S G, et al. Paleo-temperature evolution and water soluble gas in Sinian reservoirs, Anpingdian-Gaoshiti structural zone, Central Sichuan Basin. Journal of China University of Geosciences. 2008. 19(6): 707-714 (in Chinese)

Yuan H F, Xu G S, Wang G Z, et al. Phase evolution during hydrocarbon accumulation and exploration prospect for Sinian reservoirs in the Central Sichuan Basin, China. Journal of Chengdu University of Technology (Science \& Technology Edition). 2009. 36(6): 662-668 (in Chinese)

(Edited by Hao Jie) 